\title{
Los nacionalistas católicos de Cabildo y la educación durante la última dictadura en Argentina/
}

\section{The Catholic nationalists of the Cabildo and education during the last dictatorship in Argentina}

\section{Laura Graciela Rodríguez}

Universidad Nacional de La Plata/CONICET

de Universidad Nacional General Sarmiento, Argentina

El autodenominado Proceso de Reorganización Nacional (1976-1983) diseñó y aplicó una serie de medidas desde el Ministerio de Cultura y Educación y buena parte de ellas recibieron la atención de los redactores de la revista Cabildo. Los responsables de esta publicación se reconocían como los máximos exponentes del nacionalismo católico argentino, ideología de derechas y antisemita que teñía decididamente todas sus interpretaciones sobre lo que ocurría. En el presente artículo analizaremos cuáles fueron sus opiniones respecto a la política educativa.

PAlABRAS ClAVES: Nacionalistas católicos; Revista Cabildo; Última dictadura; Argentina.

The Proceso de Reorganización Nacional (1976-1983) designed and implemented a series of measures from the Ministry of Culture and Education and most of them received the attention of the drafters of the Cabildo publication. Those responsible for this publication were recognized as the greatest exponents of the Argentine Catholic nationalism, ideology of right and anti-Semitic that strongly subjects all their interpretations of what was happening. In this article we'll discuss what their views on education policy were.

Keywords: Catholic Nationalism; Publication Cabildo; Last dictatorship; Argentina. 
No creo en la democracia, no creo en el sufragio universal, no creo en la soberanía del pueblo, no creo en el constitucionalismo moderno (...) Me produce una infinita náusea todo esto. ¿Por qué no cree en la democracia? Por que soy católico y un católico coherente no puede ser democrático por que el primer acto democrático de la historia crucificó a Jesucristo y dejó en libertad a un delincuente. (Antonio Caponnetto, director de Cabildo, julio de 2009). ${ }^{1}$

Entre 1930 y 1966 se organizaron en la Argentina cinco golpes militares que estuvieron intercalados con regímenes democráticos de distinto tipo. El 24 de marzo de 1976 los integrantes de las tres Fuerzas Armadas organizaron el sexto asalto a un gobierno elegido constitucionalmente, al tiempo que se sucedían otros golpes de Estado de similares características en los países del Cono Sur Latinoamericano (Brasil, Chile y Uruguay). En comparación, la última dictadura militar en Argentina fue la más cruenta de la región. Los organismos de derechos humanos calculan que hubo alrededor de 30.000 «desaparecidos», denominación que define a las personas que fueron secuestradas por las fuerzas de seguridad y de las que no se supo el paradero durante mucho tiempo. Lo cierto es que la mayoría fue torturada en aproximadamente 340 centros clandestinos de detención distribuidos en todo el país, y/o asesinada. Un gran porcentaje ha sido identificado como trabajador de fábrica y militante sindical y casi el 6 por ciento del total como docente.

Como se ha indicado, el autodenominado Proceso de Reorganización Nacional (1976-1983) diseñó y aplicó una serie de medidas desde el Ministerio de Cultura y Educación, buena parte de ellas analizadas por los redactores de la revista Cabildo. Los responsables de esta publicación se consideraban los máximos exponentes del nacionalismo católico argentino, ideología de derechas y antisemita manifestada decididamente en todos sus análisis sobre lo que ocurría. En este trabajo pretendemos continuar con nuestras investigaciones sobre la política educativa durante el Proceso, el análisis de las trayectorias de los distintos funcionarios civiles que ocuparon la cartera y sus vínculos con el mundo católico. Buscaremos ir más allá de los discursos que pronunciaron, reconociendo quiénes escribían sobre educación y qué vínculos tuvieron con funcionarios del gobierno dictatorial.

1 http://lahoradejuancruz.blogspot.com/2009/07/entrevista-antonio-caponnetto.html, visitado el 4 de mayo de 2010. 
La bibliografía sobre las relaciones entre la Iglesia católica y el Proceso, se ha centrado en las posiciones que tomaron sus distintos integrantes frente a las violaciones de los derechos humanos. ${ }^{2}$ Sobre el nacionalismo católico de Cabildo se han escrito varios artículos que plantean distintos aspectos que van desde los orígenes en 1973, hasta fines de los años ochenta. ${ }^{3}$ De estas investigaciones y de su lectura se desprende que la publicación no estaba especializada en temas educativos, sin embargo, sus redactores se dedicaron de manera bastante regular a esas cuestiones, especialmente durante el periodo de la presidencia del teniente general Jorge Rafael Videla (1976-1981). En línea con el catolicismo más tradicional, los de Cabildo decían tener una larga lista de «enemigos», tales como «el liberalismo y el marxismo en todos sus matices, la masonería y el judaísmo, los intereses venales y el conformismo egoísta y utilitario, el progresismo religioso y la pacatería, la pederastia intelectual, los partidócratas, los espíritus cobardes, la mediocridad y la envidia». ${ }^{4}$ Partiendo de estas bases, Cabildo aspiraba a «ser un instrumento activo de la plena restauración nacional».

En líneas generales fueron muy críticos de las medidas económicas liberales y acusaron a la Junta de carecer de una línea política e ideológica definida. ${ }^{5}$ En materia educativa, los nacionalistas pretendían que el gobierno le otorgara el control total de la educación a la Iglesia Católica, como había ocurrido en España durante la dictadura de Franco, a quien admiraban. Para ello se tenía que derogar la Ley de Educación N. ${ }^{\circ} 1420$ del año

2 Mignone, 1986; Mallimacci, 1996, pp. 181-218; Zanatta, 1998, pp. 169-188; Di Stefano y Zanatta, 2000; Obregón, 2005, pp. 259-272.

3 La revista nació en mayo de 1973, ocho días antes de la asunción del presidente peronista Héctor J. Cámpora. Luego de la muerte de Juan Domingo Perón en julio de 1974 la publicación fue apareciendo con distintos nombres como El Fortín y Restauración. El tono antidemocrático y antiperonista de sus artículos llevó a que fuera clausurada tres veces por el gobierno de María Estela Martínez de Perón. Después del golpe militar de 1976, Cabildo retomó su actividad desde el número 1 y anunciando una «segunda época». Ver Orbe, 2008; Orbe, 2009; Saborido, 2005, pp. 235-270; Saborido, 2004, pp. 117-129; Saborido, 2004, pp. 209-223.

4 Cabildo, N. ${ }^{\circ}$ 26, agosto 1979, interior de tapa. Como ha señalado Martín Obregón, los obispos argentinos, frente al Concilio Vaticano II se dividieron en tres grandes grupos. Por un lado estuvieron los tradicionalistas, que eran los más intransigentes y se mantuvieron cerca del Vicariato Castrense para las Fuerzas Armadas. Por otro lado, se encontraban los obispos conservadores que habían tomado conciencia de la imposibilidad de una vuelta atrás después del Concilio. Fueron el sector más numeroso y por eso mismo, se caracterizaron por una mayor vaguedad desde el punto de vista ideológico. Los dos se diferenciaban a su vez, de los renovadores que se mostraron más tolerantes a la renovación conciliar y también presentaron diferencias internas. Obregón, 2005, pp. 42-46. 2005 , p. 250.

5 Al igual que en el gobierno peronista, uno de sus números fue prohibido. Ver Saborido, 
1884 que establecía la educación laica, gratuita y obligatoria. Hacia el final del Proceso nada de esto se concretó, lo que agudizó los ataques.

En el presente trabajo pretendemos mostrar que este grupo, a pesar de haber sido particularmente crítico de Videla, estuvo lejos de permanecer aislado de la arena política; varios de ellos integraron las estructuras del Ministerio de Cultura y Educación y tuvieron cierta influencia en determinadas áreas de esa cartera. Ahora bien, este artículo está conformado por tres apartados. En el primero, veremos que los nacionalistas católicos elogiaron una serie de medidas que se llevaron a cabo durante los dos primeros años de gobierno: la intervención a los colegios, la censura de libros, el contenido de un documento que avaló la represión en el ámbito educativo y el cierre de carreras en la Universidad. Sin dudas, estas acciones formaban parte de su propia agenda educativa. Al igual que en otros temas, se dedicaron a criticar a Videla por «equivocarse» al nombrar a los ministros de esa etapa y por ceder a las presiones de los «reformistas».

En el segundo apartado caracterizaremos las relaciones que mantuvieron Antonio Caponnetto, uno de los «especialistas» en educación, y sus aliados, con el tercer ministro del Proceso, el católico conservador Juan Rafael Llerena Amadeo. Aunque la mayoría de las notas estaba sin firma, Caponnetto escribió casi todos los artículos o bien convocaba a sus conocidos a redactarlos. Señalaremos que él y sus colaboradores estaban vinculados a distintas dependencias del Ministerio y particularmente al Consejo Nacional de Investigaciones Científicas y Tecnológicas (CONICET). Estas relaciones se vieron fortalecidas durante la gestión de Llerena Amadeo y les permitieron organizar distintas actividades educativas desde las cuales difundieron su ideología más allá de Cabildo. En el último apartado estudiaremos cómo evaluaron la gestión de Llerena Amadeo. Previsiblemente, dijeron que su mandato fue el mejor de los tres, pero que no pudo cumplir con la agenda de los católicos porque Videla le impuso «limitaciones» de diverso tipo.

\section{Los ministros Bruera y Catalán (1976-1978). Elogio a la represión}

El Ministerio de Cultura y Educación fue ocupado por cinco ministros civiles y durante dos periodos por el ministro del Interior, el general Albano E. Harguindeguy, todos ellos alineados en las filas de los católicos conservadores. Las disputas entre los integrantes del gobierno hicieron que la car- 
tera educativa resultara la más inestable de todas durante la presidencia de Videla. Los de Cabildo dieron a conocer varios comentarios en este sentido, mientras transcurrían las gestiones de los tres primeros mandatarios: Ricardo Pedro Bruera, Juan José Catalán y Juan Rafael Llerena Amadeo.

Siguiendo la idea de que «era imposible ignorar el papel que jugaban la cultura y la educación en los planes de la revolución marxista», desde los primeros meses del Proceso las fuerzas de seguridad comenzaron a intervenir colegios públicos y privados católicos. La Iglesia protestó en privado por estas medidas, ya que si bien en líneas generales las autoridades religiosas apoyaban estas acciones, lo que reclamaban al gobierno era que fuera la propia institución la que investigara y sancionara las transgresiones en sus establecimientos. ${ }^{6}$

Durante la gestión del ministro Ricardo P. Bruera, uno de los casos más resonantes fue la intervención al colegio San Miguel de la Capital Federal. A través de la agencia oficial Telam se dio a conocer un comunicado de la Unión de Padres de Familia adonde se acusaba a los sacerdotes responsables de la conducción de ese establecimiento, de haber realizado «una abierta apología de la subversión» y elogiar a sus «máximos dirigentes». ${ }^{7}$ El comunicado estaba firmado por un «padre de familia», Alejandro Cloppet, y en él se señalaba que «lamentablemente», en enero de 1976, un grupo de sacerdotes había asumido el control y aprovechó la oportunidad para imprimir «volantes de la organización subversiva declarada ilegal en el año 1975». Terminaba afirmando que dicha Unión de Padres nunca fue reconocida por el superior de la Orden y que a los hijos de muchos de sus miembros se les negó la reinscripción al finalizar ese año lectivo. En este caso, la intervención fue ordenada por el director de la Superintendencia Nacional de Enseñanza Privada (SNEP). Dicha medida fue apelada por los sacerdotes e, inesperadamente para los sectores más intransigentes, la justicia dictaminó la suspensión de la orden.

Cabildo se ocupó de este hecho y tituló la nota como «Otro Fallo Lamentable». ${ }^{8}$ Sostenía que la justicia había dictado una sentencia «a contrapelo de las necesidades del país y con aparente olvido de que el estado de guerra interna requería una especial concepción del derecho y una adecuada aplicación de sus normas concretas». El juez a cargo, el doctor

6 Verbitsky, 2006.

7 Clarín, 22 diciembre 1976, p. 10.

8 Cabildo, N. ${ }^{\circ} 10$, septiembre 1977, p. 8. 
Cermesoni, dictó un nuevo pronunciamiento que, aseguraba, «tendría gravísimas consecuencias en el campo cultural de la lucha antisubversiva». Explicaba que ese juez no sólo había dejado sin efecto la intervención del registro de alumnos del colegio San Miguel, sino que también había rechazado el recurso de amparo presentado por los padres de alumnos de ese centro, cuya inscripción les había sido negada. Según creía el responsable de la nota, el problema era que estos jueces tenían limitada su visión por las «anteojeras del liberalismo y del positivismo jurídico» y por el camino de la «ciega aplicación de la ley», y al final terminaban siendo «cómplices inconscientes de la subversión».

En el mismo número, el cronista criticaba por ese tema al presidente y al director de la revista del conservador Consejo Superior de Enseñanza Católica o CONSUDEC. En el artículo «CONSUDEC y la Subversión en la Enseñanza Privada» volvía a decir que el Estado, en el cumplimiento de obligaciones elementales, debía «extremar su celo en la detección y eliminación de los focos de adoctrinamiento subversivo en la Enseñanza Privada». ${ }^{9}$ De acuerdo a la revista, el problema fundamental era que el CONSUDEC no quería aceptar que existía una extendida «penetración» entre sus filas. La subversión había elegido a la Iglesia y a sus instituciones educativas como «terreno predilecto de su siembra ideológica y de su accionar práctico», y esto «nos había llevado a poner especial énfasis en el problema de la subversión en la enseñanza católica». El redactor advertía que las familias católicas todavía «sentían una falsa seguridad en relación con sus hijos, presumiendo que sólo el hecho de asistir a un colegio católico o de formar parte de una organización juvenil de la Iglesia les garantizaba una total inmunidad frente al contagio subversivo». Por su parte, el director del periódico Consudec escribió una nota rechazando estas acusaciones vertidas por Cabildo. ${ }^{10}$

Seguidamente, se publicó una solicitud de la Unión Argentina de Defensa Educación Católica o UADEC, que tenía a Eduardo Caminotti como secretario y a Luis G. Bedzent como presidente. Allí argumentaban que el Estado debía salvar al país con una verdadera Ley de Educación que volviese a los valores de la familia, a la Patria común y a la existencia de Dios. ${ }^{11}$

\footnotetext{
9 Ibidem, pp. 43-46.

10 Sobre el periódico Consudec durante el Proceso y esta polémica con los de Cabildo, ver Rodríguez, 2010a.

11 Cabildo, N. ${ }^{\circ}$ 10, septiembre 1977, pp. 46-48.
} 
En la misma página apareció uno de los pocos artículos sobre educación firmados por Antonio Caponnetto, adonde se declaraba a favor de la censura de un texto católico. Se mostraba de acuerdo con el arzobispo de La Plata, monseñor Antonio Plaza, y el gobernador de la Provincia de Buenos Aires, el general Ibérico M. Saint Jean, quienes habían prohibido la circulación del libro Dios es fiel, de la hermana Beatriz Casiello. ${ }^{12}$ El conflicto se había dado porque, tanto el Equipo Episcopal de Catequesis como el Equipo Episcopal de Teología, evaluaron positivamente el contenido del texto y aseguraron que no contenía ninguna afirmación errónea ni negacion alguna de la Doctrina Católica. De hecho, a partir de este dictamen, Dios es fiel sólo se prohibió en la Provincia de Buenos Aires y no en el resto del país. ${ }^{13}$ Caponnetto se dedicó a apoyar enérgicamente a Plaza y a mostrar el «parafraseo imbécil de naderías marxistoides» que había en el libro. Para ejemplificar, mostraba que en una parte se le proponía al alumno el siguiente ejercicio: «Escribe una carta a los pueblos ricos que gastan dinero en armas, para que se acuerden de sus hermanos». Finalizaba preguntándose hasta cuándo las autoridades eclesiásticas iban a consentir «tanto desparpajo» y si estaban esperando que «seamos fusilados por curas bolcheviques».

Un tiempo después, la revista publicó otra nota más vinculada al cierre de colegios, esta vez en la Provincia de Córdoba. Se llamaba: «Córdoba: el Ocaso de los Brujos» y, a diferencia de lo que había ocurrido en el colegio San Miguel, Cabildo elogiaba la medida que había tomado el Gobierno. La Secretaría de Cultura y Educación de esa Provincia acababa de decretar la clausura y el cierre definitivo del instituto privado de enseñanza primaria «Leo Bovisio». ${ }^{14}$ Según Cabildo, el fundador era Santiago Bovisio, creador de la Orden de los Caballeros Americanos del Fuego (CAF) que actuaba como Ordecon (Comunidad de Ordenados). En la revista se decía que esa escuela estaba en manos de una «poderosa y tenebrosa organización judeo masónica panteísta, ocultista, esotérica, mágica, teosófica y cabalística, vinculada a Estados Unidos e Israel, entre otros». La secta del $\mathrm{CAF}$ «destilaba una religiosidad esotérica negadora de la capacidad del hombre para llegar al conocimiento de Dios mediante la teología y la Fe, al reemplazar a ésta por la magia y atentatoria del Ser Nacional por subver-

12 Ibidem.

13 Invernizzi y Gociol, 2002.

14 Cabildo, N. ${ }^{\circ}$ 21, diciembre 1978, pp. 29-30. 
sión ideológica, destructiva de la raigambre histórica del Ser Argentino». Cabildo y sus lectores «aplaudían y felicitaban por esa acción a las autoridades de la provincia mediterránea», ya que «ha ganado en Córdoba otra batalla»: la de «erradicar de su comunidad educativa este foco subversivo enquistado desde hacía treinta años».

Además de intervenir colegios y censurar libros, el ministro Bruera ordenó intervenir también las universidades, declaró cesantes a cientos de profesores y mandó cerrar distintas carreras, entre ellas las de Sociología, Psicología y Antropología. ${ }^{15}$ Haciéndose eco de estas medidas, en la revista se dio a conocer un artículo denominado «Antropología y Subversión», adonde se sostenía que «era sabido» que en 1955 «el marxismo bien pensante de los Romero y los Risieri Frondizi» comenzó la tarea de «demoler las bases más firmes de nuestra auténtica nacionalidad» y sentó las bases de tres carreras que serían «las piezas clave de esa estrategia disolvente: las de Sociología, Psicología y Antropología». ${ }^{16}$ A esta altura del Proceso, se preguntaban, «¿quién podría ignorar que esas 'profesiones' aparecían sintomáticamente repetidas en el currículum de los guerrilleros?» Por ejemplo, la Antropología, tras la excusa de que era materia que tenía como campo de observación y estudio a las poblaciones marginadas, resultaba un «campo propicio para reclutar e instruir a sus huestes subversivas y soliviantar a los pobladores de esos lugares». Asimismo, los antropólogos aprovechaban los viajes de investigación pagados por el Estado para «vender piezas arqueológicas» $\mathrm{y}$ «comprar armas».

El redactor de Cabildo felicitaba al ministro por haber clausurado esas tres carreras en varias universidades. Sin embargo, advertía que había dejado abierta Antropología en Buenos Aires (UBA), Misiones y Comahue, adonde aún continuaban «agazapados en cargos docentes, elementos altamente comprometidos con la subversión apátrida». También hacía notar que varios de los profesores declarados prescindibles en la UBA fueron «inmediatamente contratados en otras universidades». En este sentido, el cronista afirmaba que, si bien Bruera era un «técnico» y un «anodino», había tenido buenas ideas para la universidad, pero fue Videla quien «mandó congelar todo lo que pudiera irritar al reformismo y congeló los proyectos que pudieran dar lugar a descontentos pasibles de ser capitalizados por los enemigos del gobierno». ${ }^{17}$

15 Sobre la política universitaria del Proceso, ver Rodríguez y Soprano, 2009.

16 Cabildo, N. ${ }^{\circ}$ 16, mayo- junio 1978, pp. 30-31.

17 Cabildo, N. ${ }^{\circ}$ 41, marzo 1981, pp. 24-25. 
Si al ministro Bruera los nacionalistas católicos le reconocían algún mérito, fueron mucho más críticos con su sucesor Catalán. A poco de asumir el cargo, este ministro dio a conocer la Resolución N. ${ }^{\circ} 538$ que disponía la distribución, en todos los establecimientos educativos del país, del documento denominado Subversión en el ámbito educativo. Conozcamos a nuestro enemigo. El manuscrito se había hecho para facilitar la «comprensión del fenómeno subversivo que vivía la Argentina de esos días» y a los fines de «explicar en forma directa y clara los principales acontecimientos sucedidos y de brindar elementos de juicio sobre el accionar del marxismo».

Los de Cabildo elogiaron entusiasmados su contenido, decían que se trataba «del mejor documento oficial jamás redactado por el Estado Argentino y relativo a la subversión marxista» ${ }^{18}$ Los había «sorprendido» por la «seriedad, la agudeza, la franqueza, la lucidez y la veracidad» con que había sido escrito, pero creían que el ministro había «hecho un sub uso del documento», ya que la distribución en los institutos de enseñanza fue «harto deficiente». El columnista se preguntaba si esto había sido por un defecto de la burocracia típico de la gestión de Catalán, o bien era «un fino sabotaje a su distribución». Lo cierto, continuaba, era que muchos colegios y profesores de la Capital y del interior del país todavía lo desconocían, y lo más grave era que a ninguna universidad nacional o privada se le había hecho llegar un solo ejemplar de este folleto.

Concluía que esto no podía ser casual y que seguramente Catalán había dictado alguna consigna de no distribuirlo en general, y en particular a las universidades. De acuerdo a su punto de vista, el problema estaba en que el ministro había sido dirigente de la Federación Universitaria Argentina en Tucumán cuando «la izquierda» copó la universidad después del derrocamiento de Perón. Era «evidente que el texto provenía de los militares y que no había sido escrito por civiles y mucho menos por Catalán», a quien le endilgaba «ambiciones electoralistas» y por esos motivos habría prohibido la difusión del folleto en las universidades, porque «calculaba que eventualmente con esos actores iba a tener que buscar un acuerdo en el futuro». Remataba su nota con la frase: «No hay nada peor que un político con mentalidad electoralista metido en un gobierno de facto». En síntesis, el nombramiento de Catalán había sido el principal «error» de Videla.

18 Cabildo, N. ${ }^{\circ}$ 18, septiembre 1978, pp. 31-32. 
Después de los mandatos de Bruera y Catalán, hubo un periodo en el que el presidente de facto no encontraba sustituto para el Ministerio de Cultura y Educación (cuestión que ya había pasado cuando le pidieron la renuncia a Bruera). Mientras asumía por segunda vez como suplente el general Albano Harguindeguy, las especulaciones sobre quién sería el futuro mandatario eran frecuentes en la prensa.

En la revista aprovecharon esta situación para criticar una vez más a Videla. Publicaron una nota que se titulaba «La Sencilla y Ardua Búsqueda de un Ministro», adonde comentaban que el gobierno llevaba mes y medio sin encontrar ministro de Educación y que los militares no se ponían de acuerdo con el nuevo mandatario, «no porque no alcance el grado de excelencia que ese cargo requiere, sino porque no da justo en el grado de mediocridad que se le exige». ${ }^{19}$ De acuerdo con el cronista, el candidato podría «ser un figurón más o menos bobo que se pone en manos de las trenzas administrativas y se dedica a decir vaguedades por televisión, entre otras cosas». Lo mejor que podrían hacer «sería congelar la vacante de la cartera, o, en todo caso, mandar un sargento que vigile el cumplimiento de los horarios y la limpieza de las paredes y vaya tirando hasta que llegue el gobierno de probeta que la Reorganización parecería proponerse constituir en su democrático heredero». Por este camino, apuntaba, no había garantía de que «a la primera de cambio el campo de la Educación no vaya a ser copado nuevamente por la izquierda». A dos años y medio, el proceso en el sector educativo y cultural era «cuando menos desconcertante». En el plano de la cultura pasaba lo mismo y esto podía provocar «una nueva embestida del terrorismo cultural».

\section{Los nacionalistas y el CONICET}

Luego de las dos breves gestiones de Bruera (marzo 1976 - abril/mayo 1977) y de Catalán (junio 1977- agosto 1978), la cúpula militar escuchó los consejos de la jerarquía eclesiástica. Los cardenales Pironio, Primatesta y Aramburu se reunieron con Videla y le sugirieron que pusiera a Juan Rafael Llerena Amadeo al frente de este Ministerio. Llerena Amadeo era un católico conservador, de profesión abogado, pertenecía a la Corporación de Abogados Católicos «San Alfonso María de Ligorio», una de las organiza-

19 Cabildo, N. ${ }^{\circ} 19$, octubre 1978 , p. 5. 
ciones de profesionales de laicos que había creado la Iglesia Católica en los años treinta y de la cual eran miembros varios funcionarios del Proceso. Había sido subsecretario de Educación del ministro José Mariano Astigueta (1967-1969) durante la presidencia del general Juan Carlos Onganía en la dictadura anterior. Colaboraba con el diario La Nación, trabajaba como profesor de las universidades Católica Argentina y del Salvador, y desde 1976 era secretario académico de la Facultad de Derecho de la Universidad Nacional de Buenos Aires o UBA.

Antonio Caponnetto y su grupo estaban vinculados con Llerena Amadeo por afinidades ideológicas -estaban del lado de los católicos preconciliares- y por medio de una estrecha y compleja trama de institutos y fundaciones privadas que funcionaron en el CONICET, en las áreas de «Ciencias Sociales» y «Ciencias Humanas y Morales». Ellos eran responsables del Instituto de Ciencias Sociales (ICIS), la Fundación Argentina de Estudios Sociales (FADES), la Asociación para la Promoción de Sistemas Educativos no Convencionales (SENOC), la Asociación para la Promoción de los Estudios Territoriales y Ambientales (OIKOS) y el Instituto Bibliográfico Antonio Zinny (IBIZI), a cargo del profesor de historia Jorge Clemente Bohcziewicz. En 1977, el entonces abogado y profesor de la UBA, Juan Rafael Llerena Amadeo, había contribuido con aportes monetarios a la creación de la SENOC y luego formó parte del directorio. Estas buenas relaciones no estuvieron exentas de tensiones, en tanto Llerena Amadeo estaba estrechamente relacionado con las autoridades católicas del CONSUDEC, a quienes Cabildo había atacado, como vimos en el apartado anterior.

Cuando Llerena Amadeo era ministro, Caponnetto y sus aliados organizaron un «curso de perfeccionamiento docente» que había sido aprobado por la Superintendencia Nacional de Enseñanza Privada (SNEP) del Ministerio de Cultura y Educación. Es decir, a diferencia de otros cursos que se ofrecían en la revista — por ejemplo, los de Historia Argentina de Federico Ibarguren-, éste otorgaba puntos a los docentes del Sistema. El curso se llamaba «Corrientes pedagógicas contemporáneas: su incidencia en la tarea escolar» ${ }^{20}$ y perseguía los objetivos de esclarecer acerca de las teorías pedagógicas modernas, sus aciertos, carencias y desajustes; comprender la repercusión en la vida escolar de aquellos desajustes y carencias; analizar críticamente y revisar las áreas pedagógicas de la enseñanza

20 Cabildo, N. ${ }^{\circ} 23$, marzo- abril 1979, p. 2. 
media; estudiar los fundamentos de la pedagogía católica; ejercitar y resolver problemas vinculados a: textos, planificación, disciplina, contenidos y metodología de estudio.

Las exposiciones teóricas estaban a cargo de Antonio Caponnetto (ICIS- FADES): «Actual Panorama Pedagógico. El caso de las Ciencias Sociales» $;{ }^{21}$ el padre José Luis Torres- Pardo: «La catequesis moderna»;22 Jorge N. Ferro (SENOC): «La enseñanza de las Humanidades»; Rafael L. Breide Obeid (OIKOS): «La enseñanza de las Letras»; Juan Carlos Montiel (SENOC): «La enseñanza de las Ciencias Naturales»; Witold R. Kopytynski: «La enseñanza de las Ciencias Exactas» y Roberto J. Brie (ICIS-FADES): «Concepción Católica de la Pedagogía». De los «trabajos prácticos» se encargaban el doctor Edgardo Palavecino, Antonio Caponnetto y Juan Carlos Montiel.

Los docentes interesados en dicho curso debían inscribirse en el Instituto de Promoción Social Argentina (IPSA), al cual estuvo vinculado el nacionalista admirador de Santo Tomás de Aquino, Carlos Alberto Sacheri, muy relacionado con el grupo de Verbo, que fue presidente de la organización filo nazi «Ciudad Católica» y trabajó en el CONICET y en la Fundación para la Educación, la Ciencia y la Cultura (FECIC). ${ }^{23}$

Antonio Caponnetto era profesor de Historia egresado de la Facultad de Filosofía y Letras de la UBA y trabajaba como docente en la Facultad de Derecho de la misma universidad. En los años del Proceso fue becario del CONICET con sede en ICIS-FADES, y cumplía funciones de tesorero en FADES, cuyo presidente era el filósofo Roberto José Brie, quien además era su director de beca. En ocasiones, Antonio escribía con su hermano Mario, quien estaba casado con la hija de uno de los máximos representantes de esta corriente ideológica, Jordán Bruno Genta. ${ }^{24}$

Mario Caponnetto era médico graduado en la UBA y había realizado los cursos que dictaba su suegro. Integraba la FECIC y, junto a Brie, la SENOC. Pertenecía al Consorcio de Médicos Católicos, a la Corporación

21 Caponnetto también daba cursos de «formación doctrinaria para jóvenes», entre ellos el de Introducción al pensamiento nacionalista.

22 El padre Torres Pardo nació en España y llegó al país en 1968. Con la ayuda de los monseñores Adolfo Tortolo y Victorio Bonamín creó en Rosario el Instituto Cristo Rey en 1980 integrado por «sacerdotes y hermanos coadjutores» y la Legión de Cristo Rey, formada por laicos en sus dos ramas: masculina y femenina, conocida por sus posiciones extremas.

23 Sobre Sacheri, ver Ranalletti, 2009, pp. 249-280.

24 Sobre Genta, ver Senkman, 2001, pp. 275-320; Ferrari, 2009. Genta y Sacheri fueron asesinados en 1974 por grupos armados de izquierda. 
de Científicos Católicos y a la Sociedad Internacional Tomás de Aquino (SITA). El abogado y profesor en letras, Breide Obeid, de OIKOS, era empleado de planta del Ministerio de Cultura y Educación y trabajaba en el área universitaria, como profesor de la Universidad Católica Argentina, además de formar parte de la SITA. Jorge Norberto Ferro era egresado en Letras, profesor en la Universidad Católica de La Plata, becario de CONICET, con sede en SENOC, y especialista en literatura española medieval. Juan Carlos Montiel, profesor de Biología, egresado de La Plata y vinculado al SENOC, era propietario y director de un colegio secundario, privado y católico ubicado en el distrito de San Miguel, provincia de Buenos Aires.

Todos ellos solían escribir, no tanto en Cabildo sino en revistas católicas afines al Proceso, entre ellas Verbo, Mikael y Estrada. ${ }^{25}$ Otros conocidos nacionalistas católicos que pertenecían a OIKOS, como Patricio Randle o Aníbal D’Angelo Rodríguez, publicaron en Cabildo en más de una ocasión. Como pudo apreciarse, una figura clave de este grupo fue Roberto José Brie, egresado de Filosofía por la UBA, que había sido profesor de Sociología, Filosofía y Metodología de la Investigación en varias universidades nacionales y en la Católica de La Plata. Durante la dictadura de Onganía, entre 1966 y 1969, fue decano de la Facultad de Filosofía de las Universidades Nacionales del Litoral y de Rosario (1966-1969). Cursó estudios de doctorado en Alemania y era integrante de la Sociedad Tomista Argentina. ${ }^{26}$ La importancia de Brie residía en que fue uno de los principales responsables del destino de los dineros del CONICET, ya que en esos años integró el Comité Ejecutivo y el Directorio.

Los representantes de estos institutos organizaron con subsidios del CONICET diversas actividades como simposios, jornadas o encuentros adonde exponían a un público numeroso sus posturas acerca de lo que había que hacer en el campo educativo. De la misma manera, con esos dineros financiaron sus propias publicaciones. En suma, el CONICET costeó, durante los años del Proceso, buena parte de las actividades de los nacionalistas católicos. Una vez finalizada la dictadura, las autoridades del

25 Sobre la revista Verbo ver Scirica, 2006. Sobre Estrada ver Rodríguez, 2010; acerca de la revista Mikael ver Doval, 2001, pp. 121-146.

26 http://cablemodem.fibertel.com.ar/sta/prof_dr_brie.htm, visitado el 2 noviembre de 2009. Sobre Brie y su actuación en la Universidad, ver Apaza (2009); acerca de la participación de Brie en grupos nacionalistas ver Orbe (2008). Sobre la política del CONICET durante el Proceso, ver Bekerman (2008). 
CONICET en democracia denunciaron a los responsables de estos y otros institutos por malversación de fondos públicos. ${ }^{27}$

Dijimos que Caponnetto se autodefinía como un «especialista» en educación. Había escrito varios artículos en Cabildo y en otras revistas y en mayo de 1981 publicó un libro que sintetizaba su trabajo de los años anteriores; se llamaba Pedagogía y Educación. La crisis de la contemplación en la Escuela Moderna, y sus editores fueron Cruz y Fierro. En Cabildo se anunciaba que Juan Carlos Montiel presentaría la obra el 22 de mayo. ${ }^{28}$ En la solapa se aclaraba que el autor tenía publicados otros manuscritos como «Las falsificaciones históricas», «Aportes para una historia del Modernismo en la Argentina» y «La ciudad y la Virgen». Se decía que reflejaban sus «inquietudes religiosas, históricas y del pensamiento histórico hispanoamericano». Caponnetto le dedicaba el libro a Jordán Bruno Genta y explicaba que pretendía mostrar que la única «Pedagogía verdadera» era la «Pedagogía de los Arquetipos» planteada por Genta.

En la siguiente edición de Cabildo se publicó un comentario en la sección fija denominada «Libros», ubicada en las últimas páginas. El autor, Álvaro Riva, sostenía que la tesis «central y sencilla del libro» era que la educación «debía rescatar la interioridad del hombre para elevarlo hasta Dios y ello por miedo de la contemplación. Esto pondría en movimiento los mecanismos más íntimos y más misteriosos de la personalidad humana y limpiaría al Hombre Moderno de las bajezas de su formación y lo liberaría del proceso de desacralización que lo iba cercando hasta asfixiarlo». ${ }^{29}$ Este libro, como otros textos de los nacionalistas católicos que se publicaron en esa época, circularon como material de lectura obligatoria en distintas instituciones educativas, varias de ellas dependientes de las Fuerzas Armadas.

27 Informe sobre investigaciones de hechos ocurridos en el CONICET (Consejo Nacional de Investigaciones Científicas y Técnicas). Período 1976-1983, Buenos Aires, EUDEBA, 1989. El ex ministro Ricardo P. Bruera fue nombrado director de un nuevo instituto del CONICET, el Instituto Rosario de Investigaciones en Ciencias de la Educación (IRICE) creado en julio de 1977. Bruera también fue denunciado por malversación. Es preciso señalar que en 1992 Antonio Caponnetto entró a carrera del CONICET con sede en el IBIZI como investigador adjunto con dedicación exclusiva y continúa hasta hoy. Después de la muerte de Curutchet, Caponnetto asumió como director de la revista Cabildo y lo sigue siendo en la actualidad. Es decir, la relación de los nacionalistas católicos con el CONICET ha continuado en democracia.

28 Cabildo, N. ${ }^{\circ}$ 42, marzo 1981, pp. 33-34.

29 Cabildo, N. ${ }^{\circ} 43$, junio 1981 , p. 34. 


\section{La Ley Universitaria y la asignatura Formación Moral y Cívica}

De todos los ministros del Proceso, Llerena Amadeo fue el que más tiempo duró en el cargo - dos años y casi cuatro meses-. Dadas sus afinidades con los nacionalistas católicos, resultó el único mandatario que recibió elogios por parte de los redactores de Cabildo. Bajo su gestión concretó tres medidas que fueron comentadas en la revista: la sanción de la Ley Universitaria, el cierre de la Universidad Nacional de Luján y la creación de la materia Formación Moral y Cívica.

A principios de 1979 el ministro hizo circular un anteproyecto de Ley Universitaria. A los fines de contribuir al debate, la revista publicó un «Programa Mínimo de 20 Puntos para la Educación Argentina» elaborado por el geólogo Raúl Alberto Zardini, ${ }^{30}$ un peronista de derechas que había sido nombrado decano de la Facultad de Ciencias Exactas de la UBA durante la gestión del ministro peronista Oscar Ivanissevich y del rector Ottalagano. En julio de 1975 la organización armada Montoneros puso una bomba en la casa de Zardini, según señalaban, en represalia por la persecución a militantes de esa agrupación en la Universidad. Durante el Proceso, fue director del Departamento de Ciencias Geológicas de la Facultad de Ciencias Exactas y Naturales de la UBA y estaba al frente de un proyecto financiado por el CONICET.

En el Programa Mínimo, el geólogo dedicaba la mitad de los puntos al «problema de la universidad». Con respecto a los niveles primario y secundario, proponía, entre otras cosas, prohibir la educación mixta para el colegio secundario (igual que hizo el franquismo) y establecer la doble escolaridad. Por un «problema de dignidad nacional», Zardini decía que había que rechazar todo intento de financiamiento por parte de organismos o instituciones internacionales. Creía que la Universidad había sido «casi sin interrupción desvirtuada y transformada en el verdadero botín del marxismo» y por esa razón se debía «detener el crecimiento desmesurado». Tenía que ser gobernada en los asuntos académicos por los profesores bajo rígidas y claras pautas gubernamentales; los docentes serían seleccionados por sus pares; debían aumentarse las dedicaciones exclusivas y eliminar las simples y había que «erradicar totalmente la idea del concurso». Los profesores exclusivos debían quedar habilitados para ejercer tareas de «asesoramiento privado», como una forma de enriquecer los conocimientos y vincularlos con la industria.

30 Cabildo, N. ${ }^{\circ} 22$, febrero 1979 , pp. 31-32. 
En medio del debate público sobre una nueva norma para la Universidad, el redactor de la revista escribió: «El problema de la universidad No es Legal sino Real». ${ }^{31}$ Después de repasar las posiciones de distintos especialistas que se habían ido manifestando en el diario La Nación, el responsable de la nota explicaba que el proyecto no parecía de ningún modo peor que los anteriores, ya que «era una ley típicamente convencional y positivista que no iba a desterrar el marxismo de los claustros» ni buscaba una verdadera renovación de todo el sistema de enseñanza superior como la que reclamaba el país. Las universidades «tenían hipertrofia algunas y dispersión de otras, descontrol generalizado, carencia de investigación y saber creador, exigua dedicación tanto docente como estudiantil, etc. etc.». Finalizaba citando las palabras del arquitecto Patricio Randle, que había pronunciado en la Fundación para la Acción Social y Económica (FASE) de Córdoba. Allí había dicho que no podía creer que los militares, «que no temieron exponer su pellejo en el campo de batalla se sintiesen inseguros en el terreno universitario». La ley no servía y «Dios y la patria os demandarán por haber perdido esta preciosa oportunidad». Una vez sancionada en abril de 1980, los de Cabildo seguían opinando en el mismo sentido.

$\mathrm{Al}$ igual que en otros regímenes autoritarios, los funcionarios argentinos consideraban que las universidades eran «demasiadas». ${ }^{32}$ Con el objetivo de disminuir el número, en diciembre de 1979 Llerena Amadeo cerró la primera casa de estudios ubicada en la ciudad de Luján, en la Provincia de Buenos Aires. La medida generó expresiones de rechazo incluso de los sectores aliados al Proceso y la presión fue de tal magnitud, que el ministro debió suspender sus intenciones de llevar a cabo otros cierres. ${ }^{33}$ Respecto a la clausura de la Universidad Nacional de Luján, la revista calificó de «excelente» la medida, que buscaba cumplir con la «labor de higienización intelectual del país, tan necesaria y tan vital para evitar que se repita el ciclo de marxistización de la juventud del cual estamos saliendo». ${ }^{34}$ De acuerdo a su versión, cuando a Llerena Amadeo le dijeron «que continuase clausurando universidades como la de Lomas de Zamora o la de Catamarca u otras más que, al fin y al cabo, eran tan lamentables o más que la de Luján», el ministro contestó «Seré un poco loco pero no soy tonto».

31 Cabildo, N. ${ }^{\circ}$ 26, agosto 1979, pp. 28-31.

32 Los ideólogos del franquismo también creían que el número de universidades era excesivo; ver Morente Valero, 2005, pp. 179-214.

33 Respecto a este episodio del cierre de Luján, ver Rodríguez y Soprano, 2009.

34 Cabildo, N. ${ }^{\circ}$ 41, marzo 1981, pp. 24-25. 
El columnista explicó que el mandatario debió abandonar esta medida por culpa de Videla, quien no la había apoyado lo suficiente.

En relación con la nueva materia de Secundaria, Formación Moral y Cívica, Antonio Caponnetto firmó una nota titulada «En torno a Formación Moral y Cívica». ${ }^{35}$ La inclusión de la materia fue elogiada por distintos grupos de católicos, como los nucleados en el CONSUDEC. Sin embargo, la aparición de esa asignatura fue muy criticada por organizaciones judías, evangélicas, laicas y de editorialistas de diarios como La Nación. Las distintas voces cuestionaban los contenidos católicos e incluso hubo versiones que aseguraban que Llerena Amadeo implementaría seguidamente la asignatura «Religión». Debido a estas polémicas que tuvieron una gran cobertura de la prensa, el ministro tuvo que modificar algunas partes de los programas y salir a desmentir que se pretendiera introducir la enseñanza religiosa.

En esa nota, Caponnetto retomaba los viejos argumentos que los católicos venían esgrimiendo desde los años treinta. Decía que este problema generado por la implementación de Formación Moral y Cívica sólo era inteligible «dentro del contexto total de la educación argentina». Ella fue concebida desde el éxito del Liberalismo en 1853 «como el instrumento más idóneo para la distorsión de la Inteligencia». Se trataba de «asegurar la dependencia física mediante la entrega metafísica a la ideología triunfante». Afirmaba que «la Identidad Nacional, substancialmente católica, debía atomizarse hasta su desaparición». El laicismo escolar sirvió eficazmente a estos propósitos, desde entonces, «se convirtió en la bandera de todos los enemigos de Dios y de la Patria».

Caponnetto recordaba que la mayor «desgracia» fue la Ley 1420, que el católico José Manuel de Estrada calificó de «inicua e impía». A causa de la sanción de esa norma, los docentes «llevaban en la frente el estigma 1420, a modo del 666 apocalíptico». Los programas de Formación Moral y Cívica no imponían religión alguna, pero exponían con valentía, y ése es su gran mérito, «los principios rectores de la Doctrina Católica, que, insistimos, son los principios del Orden Natural vivificados por la Revelación». Caponnetto consideraba que habían acusado a la materia de «confesional, nazicatólica, católica de derecha, preconciliar, inquisitorial, maléfica o sectaria». Todas estas expresiones fueron publicadas en los diarios La Nación, La Prensa, Buenos Aires Herald, La Luz, la Sociedad

35 Cabildo, N. ${ }^{\circ}$ 26, agosto 1979 , pp. 23-26. 
Hebraica, la Delegación de Asociaciones Israelitas Argentinas o DAIA y la revista Símbolo. Según él, «hasta los evangelistas habían adherido envalentonados». Si esto seguía así, pensaba, «mañana lo harían los mormones o tal vez, el Ejército de salvación organice una protesta». El artículo continuaba con insultos explícitos hacia los judíos. En el mismo tono se encontraba un artículo firmado con las iniciales de M. C., que coincidían con el nombre de Mario Caponnetto, hermano de Antonio. Se llamaba «El laicismo, un Viejo Mal Argentino» y concluía, entre otras cosas, que los ataques a la materia debían ser considerados como «la nueva estrategia de la subversión». Defendía la asignatura, ya que sus contenidos revelaban «un oportuno retorno a las fuentes clásicas y cristianas de nuestra cultura» y eso era un signo alentador.

Antonio escribió otra columna titulada «Más sobre Formación Moral y Cívica». ${ }^{36}$ Volvía sobre el tema porque se había convertido en uno de los «núcleos álgidos del panorama nacional y constituía un asunto de política internacional». Dos objetivos «perseguían sus impugnadores»: evitar «la cristianización de la enseñanza pública y acusar al gobierno de las Fuerzas Armadas de violar con esta asignatura los derechos humanos por ser discriminatoria, totalitaria, etc.». Explicaba que «No han sido las escuelas católicas como tales las que han engendrado guerrilleros, sino las escuelas católicas laicizadas por agentes marxistas, corrompidas sistemáticamente con instrucciones precisas del Comunismo Internacional». Terminaba diciendo que la materia debía seguir dictándose tal como estaba. En un recuadro comentaba las palabras de monseñor Laise, obispo de San Luis, en las que se pronunciaba contra «el laicismo masónico» y reivindicaba la enseñanza de la religión en las escuelas públicas. ${ }^{37}$

A principios de 1980 Alonso Quijano escribió «Cosas Veredes Sancho...», en referencia a una supuesta propaganda con la que la Asociación de la Mutual Israelita Argentina o AMIA venía proponiendo una educación judía para la patria. ${ }^{38}$ Seguía admitiendo que con los programas de la materia Formación Moral y Cívica, el Ministerio había dado un paso seguro en el recto camino, pero sería inútil llevar a Cristo a las escuelas, si en la calle seguían mandando «los mercaderes de la desintegración nacional».

36 Cabildo, N. ${ }^{\circ} 27$, septiembre 1979 , p. 7.

37 Para conocer otras intervenciones de Laise, ver Obregón, 2006, pp. 131-153.

38 Cabildo, N. ${ }^{\circ} 30$, diciembre 1979-enero 1980, p. 7. Respecto al antisemitismo explícito de la revista, ver Saborido, 2004, pp. 209-223. 
En mayo de 1981 se anunciaba en la revista que el citado obispo de San Luis dictó una «clase magistral» inaugurando la Escuela de Servicio Social «Pío XII» de la Universidad Católica de Cuyo. ${ }^{39}$ Delante del gobernador, ministros provinciales, jefes aeronáuticos y distintas autoridades, Laise afirmó que «la ley 1.420 dejó frutos nefastos para el país, siendo una de sus consecuencias la subversión marxista que asoló a nuestra patria». Con la ley se produjeron «deformaciones que en un régimen de enseñanza católica, donde se inculcara a los jóvenes los principios de la moral cristiana, nunca se hubieran producido». Terminaba asegurando que «Esas consecuencias nefastas» venían del siglo pasado, «a consecuencia de la incoherencia de los gobiernos liberales y masónicos».

En marzo de 1981 se publicó una nota sin firma titulada «Educación: Balance de 5 años». ${ }^{40}$ Después de volver a criticar las gestiones de los dos primeros ministros, el artículo se dedicaba a elogiar a Llerena Amadeo y criticar a Videla. Según Cabildo, el primero era «un hombre de formación católica que cumplió una gestión discreta dentro de las limitaciones impuestas por la mediocridad generalizada del gobierno del Proceso y acentuadas por el manoseo de un primer ministro y los dislates de un segundo titular». Durante su ministerio, «por lo menos se impidió la comisión de graves errores que podrían haber sido fatales» y se «puso una barrera a la infiltración de ideas e iniciativas de dudosa intención». Lamentablemente, seguía, en materia universitaria «el gobierno perdió la oportunidad sugerida por Bruera de proceder a una amplia reorganización».

Seguidamente, el analista pasaba a comentar el estado de la Secretaría de Cultura, que dependía del Ministerio de Cultura y Educación. Sostenía que el país necesitaba una «infraestructura mínima pero sólida basada en pocos buenos museos, bibliotecas, archivos históricos, o sea lo que no se ve pero que constituye el único acervo sobre el cual se pueden desarrollar las auténticas actividades culturales». Terminaba con un balance sobre la gestión de la Secretaría de Ciencia y Tecnología, que había sido creada por Perón y estaba llena de «activistas de ultra izquierda» y el gobierno debió «pasar la escoba» por allí. Ponderaba a uno de sus máximos funcionarios, Fermín García Marcos, porque había terminado con la intervención al CONICET y había nombrado a un «Directorio digno y capaz», entre cuyos

39 Cabildo, N. ${ }^{\circ} 42$, marzo 1981, p. 11.

40 Cabildo, N. ${ }^{\circ} 41$, marzo 1981, pp. 24-25. 
miembros se hallaba, recordemos, el director de beca de Caponnetto, Roberto Brie.

En uno de los últimos intentos de los nacionalistas católicos de elaborar una propuesta de gobierno, a principios de 1982 dieron a conocer los Principios Doctrinarios del Movimiento Nacionalista de Restauración. ${ }^{41}$ El documento tenía los apartados de «Política institucional», «Política social», «Política económica», «Política exterior y defensa nacional» y «Política cultural y educativa». En este punto afirmaban que concebían a la Cultura como la proyección de la acción del hombre sobre las cosas y sobre su propio ser, conforme «al orden natural de su inteligencia, elevado hacia el Orden Sobrenatural por la Gracia Divina». Respecto a la educación, argumentaban que en todos los niveles tenía que ser «católica y jerárquica» y que en el nivel elemental debía ser gratuita y obligatoria. En la enseñanza post primaria y secundaria el Estado debía promover y orientar a los jóvenes según sus vocaciones intelectuales, profesionales y laborales, siguiendo la «primacía de la formación integral de la persona sobre la mera acumulación de conocimientos». En la educación superior había que devolverle a la Universidad su carácter fundamental de «Escuela de Sabiduría ordenada en la búsqueda de la Verdad y a la formación de profesionales idóneos y necesarios que la nación requería». Finalizaba asegurando que «el Nacionalismo no debía renunciar a su objetivo de extirpar de nuestra Nación la peste del laicismo y con ella la Ley de Enseñanza Laica, devolviendo a la educación el sentido religioso que le es esencial y, además, propio de nuestra tradición».42

\section{Reflexiones finales}

Es preciso recordar que los nacionalistas católicos de Cabildo fueron sólo uno de los tantos grupos de derecha que venían actuando en el país desde los años veinte y cuyas complejas ramificaciones se pueden observar hasta los años de la última dictadura.$^{43}$ En este artículo pudimos apreciar que los de Cabildo estaban lejos de ser figuras aisladas de la política del

41 Cabildo, N. ${ }^{\circ}$ 49, enero 1982, pp. 18-23.

42 Ibidem, p. 23.

43 Sobre la derecha y el nacionalismo en la Argentina, ver, entre otros, Navarro Gerassi, 1968; Buchrucker, 1987; Rock, 1993; Devoto, 2002; Lvovich, 2003; McGee Deutsch, 2003; Senkman, 2001, pp. 275-320; Lewis, 2001, pp. 321-370. 
momento y participaron activamente de las cuestiones internas que se dieron en el gobierno dictatorial.

Del lado de la Iglesia, después de los conflictos ocasionados por el Concilio Vaticano II, buena parte de la jerarquía eclesiástica lo desconoció y saludó la llegada de un golpe cívico-militar en 1976. Los nacionalistas tomaron partido y coincidían en todo con los sectores tradicionalistas más intransigentes representados por monseñor Plaza y monseñor Laise. Asimismo, tuvieron una actitud ambigua con los responsables del CONSUDEC, quienes se encontraban dentro del arco amplio de los católicos conservadores.

Las ideas programáticas de este grupo reflejaban una continuidad de las formuladas por la Iglesia desde los años treinta. Estaban de acuerdo con que el «enemigo» de todos los «males» argentinos era la Ley de Educación N. ${ }^{\circ} 1420$ y que este «problema» se solucionaría con su derogación y la implantación de la enseñanza católica en todos los niveles de enseñanza. Esta propuesta se vio cumplida en parte cuando se impuso la educación católica en algunas Provincias en los años treinta y con carácter nacional a partir de $1943 .{ }^{44}$ Como han señalado otros investigadores, después de su pelea con el peronismo en 1954, la Iglesia cambió de estrategia y procuró incorporar a las estructuras del Estado a intelectuales laicos formados en sus asociaciones, con la intención de expandir el sistema privado de enseñanza creando sus propias instituciones, aunque un sector nunca perdió la esperanza de reeditar la alianza de los años cuarenta. ${ }^{45}$

Durante el Proceso, a este planteamiento histórico de la Iglesia, los nacionalistas le agregaron algunos puntos. Estaban de acuerdo con la intervención a las distintas instituciones educativas y especialmente a las católicas, el cierre de carreras y de universidades públicas, la vigilancia a los docentes, la censura de libros y se pronunciaron en contra de la educación mixta en la secundaria. Además, tuvieron sus propias ideas sobre cómo debía ser el funcionamiento interno de la Universidad. En este trabajo vimos que los nacionalistas católicos no sólo plasmaron estas nociones en la revista, sino que ejercieron cierta influencia en el CONICET y desde allí difundieron sus creencias a través de los proyectos de investigación radicados en los institutos, tesis, artículos, libros y conferencias. Esos textos continúan circulando en ciertas universidades y establecimientos militares.

44 Acerca de estos años, ver Caimari, 1995; Di Stefano y Zanatta, 2000.

45 Ver Krotsch, 1989; Mallimaci, 1996, pp. 181-218; Bianchi, 2002, pp. 143-162; Devoto, 2005, pp. 187-204; Zanca, 2006. 
Los analistas del periodo han mostrado que la última dictadura logró producir cambios profundos $\mathrm{y}$, simultáneamente, varios de sus objetivos más ambiciosos no pudieron ser concretados o debieron ser revisados a causa de los múltiples conflictos que se dieron al interior de la Junta Militar, entre los militares, y entre éstos y los civiles que integraban el Gobierno. ${ }^{46}$ En suma, de todos los ministros que ocuparon la cartera, tanto la Iglesia como los de Cabildo pusieron sus esperanzas en Llerena Amadeo, quien era un laico perteneciente a sus propias corporaciones. Al finalizar el Proceso, los nacionalistas no pudieron concretar el viejo anhelo de tener una nueva ley de educación y debieron contentarse con ciertas materias ${ }^{47}$ En definitiva, las mencionadas cuestiones internas entre los funcionarios, entre otras causas, terminaron por clausurar definitivamente este último intento de los católicos.

Recibido el 08 de abril de 2010 Aceptado el 28 de octubre de 2010

\section{Bibliografía}

Águila, Gabriela: Dictadura, represión y sociedad en Rosario, 1976/1983. Un estudio sobre la represión y los comportamientos y actitudes sociales en la dictadura, Buenos Aires, Prometeo, 2008.

Apaza, Hernán: «Las ciencias sociales bajo el terrorismo de Estado: el proyecto Sociológica, 1978-1984», ponencia presentada en XII Jornadas Interescuelas Departamentos de Historia, San Carlos de Bariloche, 2009.

Bekerman, Fabiana: «Investigación científica bajo el signo militar (1976-1983): la bisagra entre el CONICET y la Universidad», Alas. Asociación Latinoamericana de Sociología, 2009, 189-206.

Bianchi, Susana: «La conformación de la Iglesia católica como actor políticosocial. Los laicos en la institución eclesiástica: las organizaciones de elite (1930-1950)», Anuario IEHS, 17, Tandil, 2002, 143-162.

Buchrucker, Cristian: Nacionalismo y peronismo. La Argentina en la crisis ideológica mundial (1927-1955), Buenos Aires, Sudamericana, 1987.

46 Ver, entre otros, Schvarzer, 1986; O Donnell, 1997; Vezzetti, 2002; Novaro y Palermo, 2003; Quiroga, 2004; Pucciarelli, 2004; Águila, 2008; Canelo, 2008.

47 Sólo en la provincia de Santiago del Estero se impuso la enseñanza católica en las escuelas públicas. La medida se anunció a mediados de 1976 y generó comentarios críticos en algunos diarios nacionales. A principios de 1982 se dio a conocer que en la provincia de Catamarca se daría educación católica en los jardines de infantes. Esta noticia también originó repudios de diversas asociaciones. 
Caimari, Lila: Perón y la Iglesia católica. Religión, estado y sociedad en la Argentina, Buenos Aires, Ariel, 1995.

Canelo, Paula: El proceso en su laberinto. La interna militar de Videla a Bignone, Buenos Aires, Prometeo, 2008.

Devoto, Fernando: Nacionalismo, fascismo y tradicionalismo en la Argentina moderna. Una historia, Buenos Aires, Siglo XXI, 2002.

Devoto, «Atilio Dell'Oro Maini y los avatares de una generación de intelectuales católicos del centenario a la década de 1930», Prismas, 9, Bernal, 2005, 187204.

Di Stefano, Roberto y Zanatta, Loris: Historia de la Iglesia Argentina. Desde la Conquista hasta fines del siglo XX, Buenos Aires, Mondadori, 2000.

Doval, Delfina: «Una escuela de pensamiento. Universidad y Dictadura: un estilo de vida misional», en Kaufmann, Carolina (dir.): Dictadura y Educación. Tomo I. Universidad y Grupos Académicos Argentinos (1976- 1983), Madrid, Miño y Dávila, 2001, 121-146.

Ferrari, Germán: Símbolos y fantasmas. Las víctimas de la guerrilla: de la amnistía a la 'justicia para todos', Buenos Aires, Sudamericana, 2009.

Invernizzi, Hernán y Gociol, Judith: Un golpe a los libros. Represión a la cultura durante la última dictadura militar, Buenos Aires, Eudeba, 2002.

Krotsch, Pedro: «Política educativa y poder social en dos tipos de regímenes políticos: hipótesis acerca del papel de la Iglesia Católica argentina», Propuesta educativa, Buenos Aires, FLACSO, 1989.

Lewis, Paul: «La derecha y los gobiernos militares, 1955-1983», en Rock, David: McGee Deutsch, Sandra; Rapalo, María Ester et al. (eds.): La derecha argentina. nacionalistas, neoliberales, militares y clericales, Buenos Aires, Javier Vergara Editor, 2001, 321- 370.

Lvovich, Daniel: Nacionalismo y antisemitismo en la Argentina, Buenos Aires, Javier Vergara Editorial, 2003.

Mallimacci, Fortunato: «Catolicismo y militarismo en argentina (1930-1983)», en Revista de Ciencias Sociales, 4, Bernal, 1996, 181-218.

McGee Deutsch, Sandra: Contrarrevolución en la Argentina. 1900- 1932. La Liga Patriótica Argentina, Buenos Aires, Universidad Nacional de Quilmes, 2003.

Mignone, Emilio: Iglesia y dictadura, Buenos Aires, Ediciones del Pensamiento Nacional, 1986.

Morente Valero, Francisco: «La universidad fascista y la universidad franquista en perspectiva comparada», Cuadernos del Instituto Antonio de Lebrija, 8, Madrid, 2005, 179-214.

Navarro Gerassi, Marysa: Los nacionalistas, Buenos Aires, Jorge Álvarez, 1968.

Novaro, Marcos y Palermo, Vicente: La dictadura militar (1976-1983). Del golpe de Estado a la restauración democrática, Buenos Aires, Paidós, 2003.

O Donnell, Guillermo: Contrapuntos. Ensayos escogidos sobre autoritarismo y democratización, Buenos Aires, Paidós, 1997. 
Obregón, Martín: «La iglesia argentina durante el 'Proceso' (1976-1983)», Prismas, 9, Bernal, 2005, 259-272.

Obregón, «Vigilar y castigar: crisis y disciplinamiento en la Iglesia argentina en los años setenta», Anuario de Estudios Americanos, 63, 1, Sevilla, enero-junio de 2006, 131-153.

Orbe, Patricia: «Un censor nacionalista para la cultura de masas: el discurso de la revista Cabildo frente al escenario mediático argentino durante el tercer gobierno peronista», ponencia presentada en Terceras Jornadas sobre la política en Buenos Aires en el siglo XX. La Plata, 28 y 29 agosto de 2008.

Orbe, «Entre mítines y misas: la revista Cabildo y la red de sociabilidad nacionalista católica (1973-1976)», ponencia presentada en IV Jornadas de Historia Política. Bahía Blanca, 30 septiembre, 1-2 octubre de 2009.

Pucciarelli, Alfredo: Empresarios, tecnócratas y militares. La trama corporativa de la última dictadura, Buenos Aires, Siglo XXI, 2004.

Quiroga, Hugo: El tiempo del 'Proceso'. Conflictos y coincidencias entre políticos y militares. 1976-1983, Rosario, Homo Sapiens, 2004.

Ranalletti, Mario: «Contrainsurgencia, catolicismo intransigente y extremismo de derecha en la formación militar argentina. Influencias francesas en los orígenes del terrorismo de Estado (1955-1976)», Feirerstein, Daniel (comp.): Terrorismo de Estado y genocidio en América Latina, Buenos Aires, Prometeo, 2009, 249-280.

Rock, David: La Argentina autoritaria. Los nacionalistas, su historia y su influencia en la vida pública, Buenos Aires, Ariel, 1993.

Rodríguez, Laura Graciela: «Los católicos y el Proceso. El caso de la Revista Estrada», ponencia presentada en Bicentenario. Perspectivas, debates y desafios para las Ciencias Sociales, Tandil, Universidad Nacional del Centro/ Universidad Nacional de Córdoba/ Universidad Nacional de Quilmes y Universidad Nacional de La Plata, 18-20 de agosto de 2010.

Rodríguez, «Iglesia y educación durante la última dictadura en Argentina», Cultura y Religión, Iquique, Chile, 2010a (en línea, http://www.revistaculturayreligion.cl ).

Rodríguez y Soriano, Germán: «La política universitaria de la dictadura militar en la Argentina: proyectos de reestructuración del sistema de educación superior (1976-1983)», en Nouveaux Monde. Mondes Nouveaux, Paris, 2009, (en línea, http://noveauxmonde.revues.org.)

Saborido, Jorge: «El antisemitismo en la Historia argentina reciente: la revista Cabildo y la conspiración judía», Revista Complutense de Historia de América, 30, Madrid, 2004, 209- 223.

Saborido, «España ha sido condenada: el nacionalismo católico argentino y la transición a la democracia tras la muerte de Franco», en Anuario, 6, Santa Rosa, 2004, 117-129. 
Saborido, «El nacionalismo argentino en los años de plomo (1976-1983)», Anuario de Estudios Americanos, 62, 1, Sevilla, 2005, 235-270.

Schvarzer, Jorge: La política económica de Martínez de Hoz, Buenos Aires, Hyspamérica, 1986.

Scirica, Elena: «Ciudad Católica-Verbo: Discurso, redes y relaciones en pos de una apuesta [contra] revolucionaria», ponencia presentada en IV Jornadas Nacionales Espacio, Memoria e Identidad, Rosario, Universidad Nacional, octubre, 2006.

Senkman, Leonardo: «La derecha y los gobiernos civiles, 1955-1976», en Rock, Deutsch, Rapalo et al.: La derecha argentina. Nacionalistas, neoliberales, militares y clericales, 2001, 275-320.

Verbitsky, Horacio: Doble Juego. La Argentina Católica y Militar, Buenos Aires, Sudamericana, 2006.

Vezzetti, Hugo: Pasado y presente. Guerra, dictadura y sociedad en la Argentina, Buenos Aires, Siglo XXI, 2002.

Zanatta, Loris: «Religión, nación y derechos humanos. El caso argentino en perspectiva histórica», Revista de Ciencias Sociales, 7/8, Bernal, 1998, 169-188.

Zanca, José A.: Los intelectuales católicos y el fin de la cristiandad. 1955-1966, Buenos Aires, FCE/San Andrés, 2006. 